\title{
Theories on fertility intentions: a demographer's perspective
}

\section{Dimiter Philipov*}

The objections raised by Morgan and Bachrach (MB) with respect to the application of the Theory of Planned Behaviour (TPB) for studying fertility intentions are not new to the participants in the REPRO project ${ }^{1}$ who have had extensive discussions on these issues. Apparently MB put forward their topics without being familiar with the REPRO discussions; this concurrence supports the necessity of better clarifying the TPB and its application for demographic studies of fertility intentions. In my note I base myself on information received during the REPRO discussions. The purpose of the note is not to take a side in the debate. The Theory of Conjunctural Action (TCA) is not as well known to demographers as the TPB, and its exposition in the contribution by Morgan and Bachrach (MB) is too short. Rather, I use the objections to the TPB raised by MB to discuss several key issues that are of interest to demographers.

This debate can raise interest from two different scientific perspectives: social psychology and demography. Social psychologists are interested in the rigorous definition of concepts and statements, their compatibility and operationalisation. Under this perspective reproductive behaviour is a case study for testing the theory. Demographers, on their side, are mostly interested in whether a theory can help to better understand fertility intentions with the purpose to explain and predict better actual fertility behaviour. This note centres on the second view and notes by other participants in this debate highlight the socio-psychological perspective.

I start my note with a topic which is not discussed by MB: the necessity of a theory on fertility intentions. Next follows a discussion on rationality which is slightly brought up by $\mathrm{MB}$, continued with discussions on the four main objections raised by MB. In the summary I append a few additional notes.

* Dimiter Philipov, Vienna Institute of Demography, Austrian Academy of Sciences, Wittgenstein Centre for Demography and Global Human Capital, Wohllebengasse 12-14, 6th floor, 1040 Vienna, Austria. Email: dimiter.philipov@oeaw.ac.at

1 REPRO is an abbreviation for the project entitled "Reproductive decision-making in a macromicro perspective", funded by the 7th programme of the European commission, see website www.repro-project.org. 


\section{The need of a theory on fertility intentions in demography}

This is the first and foremost question which inevitably arises in a discussion about the role a theory on fertility intentions might play. Demography is an empirical science and it can be assumed that the numerous empirical findings based on the description of trends and applications of statistical models are in fact sufficient for demographers' research aims. Moreover demography centres on fertility insofar as it determines population change. Could both the TPB and the TCA be actually redundant?

Demographers analyse intentions pursuing two aims. The first is at the macro level: to get a better understanding of fertility behaviour and improve the accuracy of fertility forecasts. For example life-time intentions (known also as family-size intentions) are assumed to inform about completed cohort fertility which can be used to predict fertility levels in the short and medium run. This thinking has brought intentions in demography with the National Fertility Survey in the USA in 1955 (Westoff and Ryder 1977). Westoff and Ryder (1977) cast doubts in the predictive value of intentions and conclude that "intentions suffer all of the same vulnerabilities as other period measures" (p. 431). Recently Liefbroer (2009) for the Netherlands, and Morgan and Rackin (2010) for the USA showed that predicted fertility is not far from actual fertility, although a lot of individuals do not reach the targeted number of children while others end up with more children than they intended. One inference out of their findings is that macro-level indicators on intentions are subject to heterogeneity bias that cancels itself out. Thus it comes out that a majority of individuals failed to realise their intentions ("missed the target", to follow the expression of Quesnel-Vallée and Morgan 2003).

The latter observation is indicative about the second aim that demographers pursue with analyses of intentions: with the use of micro-level data and methods they aim to better understand what factors drive the construction and subsequent realisation or frustration of intentions. To this end econometric methods are applied to survey data. Studies on the realisation of intentions are rare as they require series of panel data which are rarely available for European countries. Cross-sectional data are more frequently available and they are used to explore the impact of various factors on the formation of intentions. For example, in a logistic regression the dependent variable measures intentions and is analysed with a set of explanatory and control variables. Relevant to this note is the way the explanatory variables are selected, although model specification is also important. Demographers usually involve theories and theoretical approaches that have gained considerable empirical support. For example economic theories on fertility emphasise the importance of income effects, opportunity costs and time allocation, the survey measures for which are included in statistical models on fertility intentions.

Thus theories and empirical findings related to fertility are mechanically transferred to studies of fertility intentions. If this approach is correct, then the 
TPB and the TCA are indeed redundant. However, hardly anyone would agree that a theory on behaviour is fully adequate for the preceding intentions as well. The findings mentioned above indicate that discrepancies between intended fertility and actual fertility at the individual level can be huge. Intentions and childbearing are driven by different sets of factors and relations, although they might have a lot of commonalities. Theories on intentions are needed to encompass the effect of those factors and relations that refer directly to intentions and not necessarily directly to childbearing. They will help to better understand how individuals construct their intentions and why some intentions get realised while others do not.

A theory on fertility can usefully support the application of a theory on intentions. Based on the economic theory on fertility and the TPB, I would place factors describing the economic situation of the individual among the background factors and in the perceived behavioural control, provided relevant measurement is available.

Demographers need a theory on fertility intentions if only for the purpose of understanding and predicting better fertility behaviour. It can only be celebrated that we at present dispose of at least three such theories: TPB, TCA, and the theoretical framework developed by Miller and Pasta (1993, 1994, 1995; see also the contribution to the debate by Miller in this volume, Miller 2011). Regrettably the Miller-Pasta framework has gained little attention in empirical applications and the TCA is still too new; it is to be hoped the three theories will increasingly be applied in demographic research.

\section{Rationality}

The concept of rationality is briefly mentioned in MB's note. Indeed the TPB does not assume rationality. Some intentions, maybe the majority, are rational but others are not. This issue goes beyond the TPB because demographers consider fertility behaviour as rational (De Bruijn 1999 provides a detailed discussion). Fundamental concepts such as direct income effects, opportunity costs and time allocation are based on the economic utility theory and hence derived on the assumption of (economic) rationality. Yet some reasons for action are nonrational. Religious people have higher fertility. Although reasons are not well established, suppose religious people rely on help that in case of need the transcendental power in which they believe will provide, or that they believe keeping religious prescriptions and rituals will help them evade hardship and disastrous events. Reproductive behaviour based on this belief can hardly be classified as rational. Demographers have studied the effect of religiosity on fertility and hence the assumption on rationality is not strictly needed. In the TPB religiosity can be included as a background factor. Rationality is not needed in the TPB because perceived attitudes, norms and control are based on beliefs which 
are composite constructs based on life experience and logical inferences but also on intuition and wishful thinking (Fishbein and Ajzen 2010, p.301). ${ }^{2}$

\section{Clear intent}

This is the first objection raised by MB which I consider from a different perspective. The concept of intention is an indication of a person's readiness to perform a behaviour (Fischbein and Ajzen 2010, p. 39). Fischbein and Ajzen (ibid.) discuss several similar expressions for a readiness to act: "I intend to engage in the behaviour"; "I will engage in the behaviour"; "I plan to engage in the behaviour". Intention is a latent construct ${ }^{3}$ and these expressions reveal much the same of its contents.

Demographers frequently formulate questions about having children with respect to "intend to have a/another child", "plan to have a/another child", "want to have a/another child", "desire to have a/another child", "expect to have a/another child". Theoretically these concepts are different; for example a desire is assumed to be independent of the current circumstances while an intention should have been formed with some awareness of the effect of their presence. Miller and Pasta in their papers discuss 'want' as a reference to a desire. Yet respondents do not distinguish between intentions, desires and expectations, as reported in early (Westoff and Ryder 1977) and recent empirical findings (Hagewen and Morgan 2005). Although a latent construct can hardly be measured perfectly, demographers' reliance on the use of one single word to measure intentions, expectations or desires as is the usual survey practice, is too optimistic.

Another related issue is measuring the intention not to have a child. It is usually done with the answer "no" to a question like the one stated here briefly only for illustration purposes: "Do you intend to have a/another child?" Yet some people may be uninterested in monitoring the outcome of their sexual behaviour and leave it to "whatever happens" or "God decides": a behaviour that differs from uncertainty in intentions. The proportion of persons with this stance is likely to be low (Barber et al. 2010) but in developing countries and probably among some minorities in European countries "God decides" is not a rarity.

\section{Clear behaviour}

This topic refers to the first part of the second objective raised by MB. The MB's objection is based on the assumption that the predicted behaviour is having a birth which is the outcome of a sequence of behaviours. This issue was a subject of debates during the REPRO meetings. The key problem here is that demographers need to improve the formulation of an intention with respect to a specified action.

\footnotetext{
Belief is a fundamental concept in the TPB just like a schema is in the TCA. Schemas are not discussed by Fischbein and Ajzen (2010); seemingly the two concepts have common features at least with respect to the way individuals construct them.

3 I did not find this statement in Fischbein and Ajzen (2010) and make use of a personal communication with I. Ajzen; any misinterpretation is my fault.
} 
According to the TPB an intention refers to a reasoned action and one of the fundamental requirements set by the TPB is that the intention should exactly match the action. This requirement is not fulfilled in a conventional survey question which asks about the intention to have a child, because it does not specify the exact action that leads to "having a child". Having a child is a reason for action; however, no action that would end with "having a child" is specified in a question like the one stated above. The relevant action, or actions, thus remain(s) ambiguous. The set of possible actions is large, for example that the individual will search for a partner, or agree with the partner to have a baby, stop using contraceptives for the purpose to achieve pregnancy, have regular sexual intercourse with the purpose of achieving pregnancy, start taking action to relax primary or secondary infertility, perform artificial insemination, adopt a child. Individuals who do not intend to have a child are likely to avoid pregnancy by choosing appropriate contraceptive methods and applying them, or by avoiding sexual intercourse. Demographers need a rigorous formulation of intentions explicitly specifying the most important actions that might end with "having a/another child". Moreover, a definition of proper action must come together with a definition of the outcome of this action. "Having a child" (preferably "achieving a pregnancy" where a biological child is considered) is an outcome, although one achieved over a sequence of actions.

Surveys usually include different questions on intentions for a biological birth and for adoption. Family planning surveys examine in detail use of contraceptives with the purpose to avoid pregnancy. So some reasoned actions that lead towards having a child are well specified and should be incorporated in the measurement of childbearing intentions.

\section{Competing intentions}

The second topic in the second objection raised by MB is that the TPB posits an outcome in isolation from other outcomes. Numerous studies in life course analysis show that young adults face competing life paths and they make a choice or a sequence of choices to select their personal path. Major choices refer to events like leaving home, marriage, having a child, starting work or education. These choices compete for the resources of the individual, such as time and its allocation. Individuals resolve the incompatibility of choices by lining them up one after the other. While a multitude of these studies refers to actual behaviour, much less attention has been paid to the corresponding intentions. An intention to have a child is incompatible with the intention to start working or to start an education because the subsequent behaviours will be incompatible. Individuals who choose a set of incompatible intentions and try to realise them all are subject to a cognitive dissonance (Festinger 1957) which can be avoided by making a choice.

From the point of view of the TPB, the stronger intention will depress a weaker one and remain the one to be realised. MB give an example with a teenage 
girl who does not intend to get pregnant but does not use contraceptives in order to show her affection to the partner. I would conclude that she submitted to the stronger intention which in this case is to maintain the love affair as compared to an occasional undesired pregnancy.

Barber (2001) expanded the TPB to include the effect of external attitudes competing with attitudes to have a child. She examined the effect of competing attitudes to childbearing such as educational attainment, career and consumer spending. In an expanded framework of the TPB Moors (2008) investigated a latent class of attitudes competing with childbearing. While these studies focused on attitudes Philipov (2009) examined competing intentions in their integrity. Studies are thus available on the issue.

\section{Stability of intentions}

This topic refers to the third issue raised by MB: the TPB models intentions at a point of time but the family-planning process unfolds over many years.

Another fundamental requirement of the TPB is that intentions should be stable in order to rightfully evaluate their realisation. Intentions are stable in the short run because in the course of time people meet unexpected obstacles that prevent their realisation. A longer time period may also lead to a change in beliefs which stay behind the constructed attitudes, norms and control measured at a certain point of time. Long-term fertility intentions such as till the end of one's reproductive life apparently do not correspond to the requirement for stability.

Long-term intentions have one specific drawback: an assessment of their realisation can only be performed after a long time period. Inferences made at that later point in time may refer to past times and hence are more of historical value than a contribution to understanding fertility at the time of assessment. Short-term intentions, such as having a child within the next two years, are much easier to assess and inferences drawn from that additional information can be useful in understanding contemporary reproductive decision-making and its subsequent behaviour. This opportunity was used by Spéder and Kapitány (2009) as well as in their contribution to the REPRO project. ${ }^{4}$ They examined two subsequent panels in four countries with questions on short-term intentions and identified the following "zigs and zags" (MB) in declared intentions to have a child during the next two years in the first wave:

- Persons who had a child were categorised as intentional parents;

- Persons who failed to have a child but declared during the second wave they intended to have one during the subsequent two years were postponers;

- Persons who failed to have a child and declared they did not want to have one during the subsequent two tears were abandoners.

4 Available at http://www.oeaw.ac.at/vid/repro/assets/docs/Summary_Realization.pdf 
The study informs in detail about these three categories empirically observed in the Netherlands, Switzerland, Hungary and Bulgaria. Apparently the categorisation can bring valuable information about changes in fertility intentions. The surveys used in these studies did not include measurement of the TPB; the latter is available in the GGS and it can be applied for useful research on the three categories.

\section{Micro-decisions in a macro perspective}

The fourth issue raised by MB is that the TPB is a micro-theory and does not incorporate the influence of the external world.

The concept 'belief' is fundamental in the TPB. Beliefs about attitudes, beliefs about norms and beliefs about control form the theoretical predecessors of intentions. Beliefs are formed under the influence of the societal environment that an individual inhabits and thus it has an effect on attitudes, norms and control and hence on intentions. I will give an example with family policies which are presumably familiar to individuals. Some individuals may find child allowances too low and will therefore neglect them. Others may find them significant for the economic support to childcare. In the latter case a woman is likely to assume that she will be able to better control her economic problems, i.e. child allowances may enforce perceived behavioural control. Individuals who value their time may find policy-induced nursery school support as significant for their decision to have a child. Given the availability of policy incentives, important significant others will evaluate them as important and may exercise normative pressure on the individual to have a child. Policies are discussed in the media and create a positive environment to have a child, hence they may affect attitudes. Apparently this conception of the effect of family policies helps to better understand their effectiveness. For example even if financial incentives and parental leaves are enforced, they may confront the negative pressure exercised on individuals by significant others or by a too modest impulse on the positive attitudes.

\section{The TPB and unintended births}

This issue is addressed several times by MB. An unintended birth is the outcome of a failed intention not to have a child. The framework of the TPB suggests a diversity of possible reasons. I would start with the most likely one: ineffective actual control. Were contraceptives used? If yes, were they used properly? Could a low-quality contraceptive device be the reason for the undesired pregnancy? Alternatively, could this woman have had a strong wishful belief that "it won't happen to me"? Fischbein and Ajzen (2010) discuss several papers reporting about the application of the TPB for use of contraceptives which refer to this topic. 


\begin{abstract}
Summary
The concerns raised by MB do not discredit the TPB. Yet they are legitimate and provoke the necessity of a more thorough interpretation and measurement of the TPB which might confront crude demographic practices. I back up Ajzen's remark, cited by MB, that demographers need to accommodate the TPB to make it appropriate for fertility research. This accommodation requires a reconsideration of fundamental concepts such as the definition of the intention itself, the reasoned action it refers to, the outcome of this action, proper definition of perceived and actual control, etc. Available measurements of the TPB such as the one examined by Billari et al. (2009) reveal that the TPB can yield valuable information. A similar measurement was applied in the GGS, although some finetuning is necessary given the restrictive requirement for a minimal number of questions.

I conclude with a topic which was not touched by MB. The TPB needs further precision in the case of a couple's intention. Each partner has his or her personal childbearing intentions. According to the TPB the partner is a significant other whose opinion is of utmost importance for the formation of the individual's intention. Yet this significant other is in the same position: his or her point of view is subject to her or his. In some cases one partner, usually the male in traditional gender regimes, may dominate with his personal opinion. Where contemporary gender relations prevail both partners will have an equal say, and in practice this requires a process similar to negotiations. The TPB is not informative on these negotiations; it would be helpful to enrich the empirical understanding of negotiations if a series of panel observations were available that inform about the process of fitting partners' intentions to each other, or about the firm dominance of one of the partner's intention over the other. Miller and Pasta (1995) discuss this issue explicitly.
\end{abstract}

\title{
References
}

Barber, Jennifer S. 2001. Ideational influences on the transition to parenthood: attitudes towards childbearing and competing alternatives. Social Psychology Quarterly 64(2): 101-127.

Barber, Jennifer S., Warren B. Miller and Heather H. Gatny 2010. The desire to become pregnant and the desire to avoid pregnancy: ambivalence, indifference, pronatalism and antinatalism. Paper presented at the annual VID Conference "From Intentions to Behaviour: Reproductive Decision-Making in a Micro-Macro- Perspective".

Billari F., D. Philipov and M.R. Testa 2009. Attitudes, norms and perceived behavioural control: explaining fertility intentions in Bulgaria. European Journal of Population 25(4): 439-466.

De Bruijn, B. 1999. Foundations of demographic theory: choice, process, context.

Doctoral dissertation published in the PDOD publication series A. NethurD

Publications. 
Festinger L. 1957. A theory of cognitive dissonance. Stanford, Ca.: Stanford University Press.

Fishbein, M. and I. Ajzen 2010. Predicting and changing behavior: the reasoned action approach. New York: Psychology Press.

Hagewen, K. and S.P. Morgan 2005. Intended and ideal family size in the U.S., 19702002. Population and Development Review 31(3): 507-528.

Liefbroer, A. 2009. Changes in family size intentions across young adulthood: a lifecourse perspective. European Journal of Population 25:363-386.

Miller, W.B. 2011. Comparing the TPB and the T-D-I-B framework. Vienna Yearbook of Population Research Vol 9:19-29.

Miller W.B. and D.J. Pasta 1993. Motivational and non-motivational determinants of child-number desires. Population and Environment: A Journal of interdisciplinary Studies 15: 113-138.

Miller W.B. and D.J. Pasta 1994. The psychology of child timing: a measurement instrument and a model. Journal of Applied Social Psychology 24: 218-250.

Miller W.B. and D.J. Pasta 1995. Behavioural intentions: which ones predict fertility behaviour in married couples? Journal of Applied Social Psychology 25: 530-555.

Moors, Guy 2008. The valued child. In search of a latent attitude profile that influences the transition to motherhood. European Journal of Population 24: 33-57.

Morgan, S.P. and H. Rackin 2010. The correspondence between fertility intentions and behavior in the United States. Population and Development Review 36(1): 91-118.

Philipov, Dimiter 2009. The effect of competing intentions and behaviour on short-term childbearing intentions and subsequent childbearing. European Journal of Population 25,4: 525-548.

Quesnel-Vallée, A. and S.P. Morgan 2003. Missing the target? Correspondence of fertility intentions and behavior in the U.S. Population Research and Policy Review 22(5-6): 497-525.

Spéder, Z. and B. Kapitány 2009. How are time-dependent childbearing intentions realized? Realization, postponement, abandonment, bringing forward. European Journal of Population 25(4): 503-523.

Westoff, C. and N.B. Ryder 1977. The predictive validity of reproductive intentions. Demography 14(4): 431-453. 
